\title{
Avaliação das Metodologias de Prensagem a Frio, SOXHLET e BLIGH DYER, na Extração do Óleo de Pinhão Manso
}

\author{
Juliana A. C. Bento, Maiara O. M. Silva, Nathália P. Silva, \\ Maria A. B. Gonçalves, Adão W. P. Evangelista, \\ Celso J. de Moura \& Reinaldo G. Nogueira
}

O cultivo do pinhão manso vem despertando grande interesse para a produção de óleo e biodiesel. Assim, este trabalho teve como objetivos comparar as metodologias de prensagem a frio, Soxhlet e Bligh Dyer, para a extração do óleo do pinhão manso e avaliar a qualidade físico-química do óleo extraído. A prensagem mostrou-se um método de extração pouco eficiente, enquanto o método Soxhlet e o Bligh Dyer forneceram resultados satisfatórios. A avaliação do óleo de pinhão manso mostrou viabilidade para sua aplicação como matéria-prima na produção de biodiesel.

Palavras-chave: jatropha curcas; extração; óleo.

The cultivation of Jatropha has aroused a great interest for the production of oil and biodiesel. Thus, this study aimed to compare the methods of cold pressing, Soxhlet and Bligh Dyer for extraction of Jatropha oil and evaluate the physical and chemical quality of the extracted oil. The press proved to be an inefficient method of extraction, while the Soxhlet and Bligh Dyer method provided satisfactory results. Evaluation of the Jatropha oil showed viability for application as raw material in the production of biodiesel.

Keywords: jatropha curcas; extraction; oil. 


\section{Introdução}

Com as mudanças climáticas mundiais, decorrentes do aquecimento global e das emissões de gases na atmosfera, faz-se necessária a busca de fontes de energia renováveis e sustentáveis ${ }^{1}$. O pinhão-manso (Jatropha curcas), oleaginosa, pertencente à família das euforbiáceas, produz sementes ricas em óleo com teor que varia entre 40 e $60 \%$, é uma planta com alto potencial para a produção de biodiesel e tem sido alvo de estudos referentes a essa produção ${ }^{2}$.

A prensagem a frio é um método muito utilizado na extração de óleo de sementes, e destaca-se por ser simples, rápido, e ainda poder ser combinado com outros sistemas de extração, como os que utilizam solventes, originando um processo misto. É importante destacar que os óleos vegetais são fontes de vitaminas, pigmentos e lipídeos fosforados que são destruídos ou não aproveitados totalmente na extração com solvente orgânico ${ }^{2}$, situação que pode ser evitada utilizando-se a extração por prensagem.

Dentre outros métodos de extração, o proposto por Bligh Dyer resulta em rendimento de lipídeos normalmente 15 a $30 \%$ maior ao obtido por outros métodos, visto que a metodologia permite a extração de todas as classes de lipídeos, polares e apolares ${ }^{3}$. Em processos industriais, a extração de óleo de sementes oleaginosas tem sido realizada utilizando-se o método de extração por solventes, processo que se equivale à extração com solventes no equipamento Soxhlet ${ }^{2}$.

Diante do exposto, este trabalho teve por objetivo avaliar a eficiência das metodologias de prensagem a frio, Bligh Dyer e Soxhlet, na extração do óleo de pinhão manso, bem como avaliar a qualidade do óleo obtido.

\section{Material e Métodos}

As sementes de pinhão manso foram adquiridas junto à Escola de Agronomia da Universidade Federal de Goiás - UFG, em Goiânia, GO, numa lavoura de pinhão manso experimental, com três anos de idade, referente à safra 2013/2014.

Para extração de óleo das sementes, utilizaram-se o método mecânico por prensagem a frio e os métodos de extração direta feita em Soxhlet e o proposto por Bligh Dyer ${ }^{4}$. A extração por prensagem a frio foi realizada em uma prensa do tipo contínua, modelo ERT 40, marca Soctt tech. Cerca de $250 \mathrm{~g}$ de sementes foram colocadas na prensa. Terminada a extração, o óleo bruto foi centrifugado em uma centrífuga, marca Excelsa II, modelo 206 BL, FANEM, a $5000 \mathrm{rpm}$ por 5 minutos.

Para a extração via Soxhlet, as sementes foram trituradas e a extração foi feita no equipamento Soxhlet (TE-044-8/50, Tecnal Equipamentos para Laboratórios), por lixiviação do óleo contido nas sementes através de seu contato com éter de petróleo por um período de quatro horas a uma temperatura de $70^{\circ} \mathrm{C}$, conforme recomendação de Melhorança Filho et al. ${ }^{5}$. Para a quantificação do teor de óleo de sementes a frio, utilizando solventes, realizaram-se os procedimentos propostos por Bligh Dyer ${ }^{4}$.

O óleo extraído por prensagem foi caracterizado quanto a parâmetros físico-químicos. A acidez foi determinada pelo método da $\mathrm{AOAC}^{6}$, o índice de peróxido foi obtido por espectrofotometria da Federação Internacional de Laticínios modificada por Shantha e Decker ${ }^{7}$, o valor de peróxido ( $\mu \mathrm{g}$ $\mathrm{g}^{-1}$ ) foi determinado pela interpolação com o ajuste linear da curva de padronização construída usando o hidróxido de cumeno (sigma) como padrão e para a determinação do índice de p-anisidina foi utilizado o método AOCS Cd 18-908.

Os resultados foram submetidos à análise de variância e, quando houve diferença significativa entre os métodos de extração de óleo de sementes, as diferenças entre os tratamentos foram verificadas de acordo com teste de Tukey ao nível de $5 \%$ de probabilidade.

\section{Resultados e Discussões}

Os métodos de extração de óleo influenciaram significativamente o rendimento do óleo das sementes de pinhão manso. O teor de óleo extraído pelo método de Bligh Dyer (36,34\%) foi o maior, sem diferir estatisticamente, no entanto, do obtido pelo método soxhlet (35,79\%) (Figura 1), mas com resultados próximos aos das médias relatadas na literatura. Materiais provenientes de diferentes acessos de pinhão manso da região de Januária, MG, foram analisados 


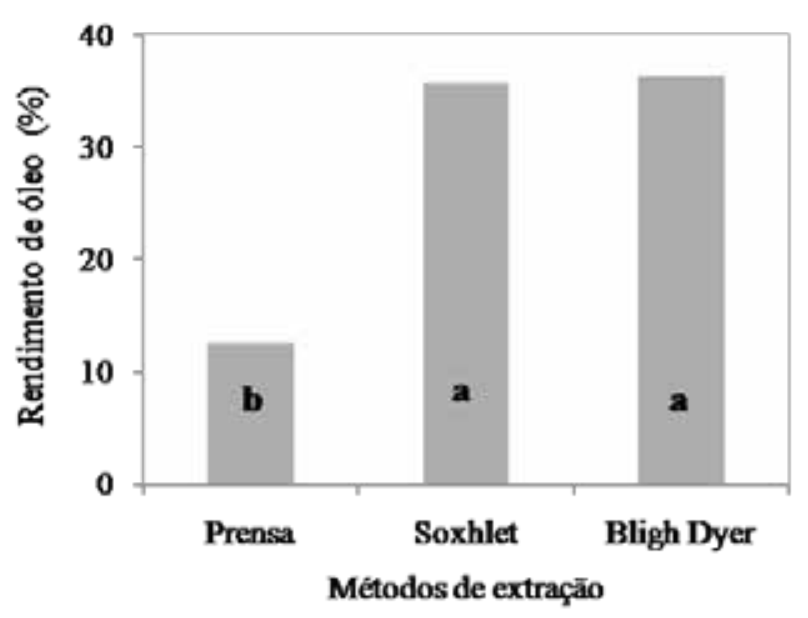

Figura 1. Rendimento de óleo de sementes de pinhão manso em função dos métodos de extração.

pela CETEC 9 e apresentaram teores médios de lipídeos extraídos pelo método soxhlet de $38,1 \%$. Em revisão realizada com sementes de pinhão manso, provenientes de São Tomé e Príncipe e de Cabo Verde, Heller ${ }^{10}$ encontrou teores totais de óleo extraído também pelo método soxhlet com média de $34,1 \%$.

O maior rendimento de óleo obtido pelos métodos Soxhlet e Bligh Dyer é justificado pelo fato de que por meio dessas técnicas é possível extrair todas as classes de lipídios das sementes. Contudo, estes métodos caracterizam-se por utilizar solventes de alto grau de toxicidade, tais como clorofórmio, metanol, éter de petróleo dentre outros ${ }^{11}$, resultando num óleo com resíduos químicos e exigindo maiores cuidados por parte do produtor, para evitar riscos com intoxicação.

A prensagem a frio apresentou o menor rendimento de extração (Figura 1), no entanto é um método que permite a obtenção do óleo sem resíduos químicos e a torta remanescente da extração de óleo pode ser destinada à alimentação animal após desintoxicação ou como adubo orgânico em culturas perenes, aumentando a renda do agricultor $^{12}$. A extração mecânica do óleo do pinhão manso foi avaliada por Pereira ${ }^{2}$ e Ferrari ${ }^{13}$, sendo observados que as amêndoas de pinhão-manso apresentaram rendimentos de $12,86,16,7 \%$ respectivamente, valores semelhantes ao encontrado neste trabalho. No entanto, este método não se mostrou eficiente, visto que a média de óleo remanescente na torta foi de $23 \pm 2 \%$, um valor consideravelmente alto.

A umidade encontrada nas sementes de pinhão manso foi de $8,5 \%$, sendo considerada recomendada para a prensagem das sementes, que deve ser inferior a $12 \%$. É importante controlar a umidade das amostras, pois este parâmetro interfere no rendimento do processo de prensagem. A presença de água até um valor específico é necessária, pois durante a prensagem o óleo removido deixa espaços vazios na torta. As moléculas de água presentes na matriz preenchem este espaço, favorecendo a remoção do óleo. Caso a umidade seja baixa, parte do óleo fica retida nos poros, reduzindo o rendimento da extração e para valores elevados de umidade, a água se mistura ao óleo e proteína dificultando a etapa de extração e purificação ${ }^{14}$.

$O$ índice de acidez encontrado no óleo de sementes de pinhão manso foi de 4,82 $\mathrm{mg} \mathrm{KOH} / \mathrm{g}$. Este valor é considerado alto pela Agência Nacional de Petróleo que estabelece que o óleo e biodiesel devem possuir índice de acidez inferior a $0,8 \mathrm{mg} \mathrm{KOH} / \mathrm{g}$, uma vez que alta acidez possui ação corrosiva sobre os componentes metálicos do motor, afetando a sua operação. Entretanto, para reduzir o valor desse índice, uma das técnicas utilizadas e regularizada pela Agência Nacional de Petróleo consiste em, após extrair o óleo, utilizar o processo de neutralização, adicionando-se uma solução aquosa de hidróxido de sódio $18 \%$ ao óleo.

$\mathrm{O}$ valor de p-Anisidina encontrado no óleo extraído por prensagem foi de 5,7, e o índice de peróxido não foi detectado. Estes resultados justificam-se pelo fato de que, no processo de oxidação, o índice de peróxidos atinge um valor máximo e, em seguida, declina, ocasionando a formação de hidro-peróxidos que se decompõem rapidamente, dando origem a produtos de oxidação secundária que podem ser determinados pelo Índice de P-Anisidina (IA), que estima o nível de aldeído, principalmente, o 2-alquenal, enquanto que o valor do índice de peroxido é a medida dos produtos 
da oxidação primaria do óleo. Valores altos de p-Anisidina caracterizam um óleo muito oxidado, ou seja, óleos em fase final de oxidação, pois com a diminuição dos peróxidos, que são transformados em produtos secundários, maiores são os valores de $\mathrm{p}$-Anisidina ${ }^{15}$. $\mathrm{O}$ índice de $\mathrm{p}$-Anisidina de 5,7 foi relativamente alto, porém dentro das especificações de qualidade do óleo para produção de biodiesel.

\section{Conclusões}

Dentre os métodos de extração estudados, a prensagem se mostrou como um método de extração pouco eficiente, enquanto que os métodos, de extração com solvente, de Bligh Dyer e o de Soxhlet forneceram resultados satisfatórios, de 36,34 e $35,79 \%$, respectivamente, sendo estes recomendados para extração de óleo de sementes de pinhão manso. O óleo de pinhão manso apresentou qualidade satisfatória, no diz respeito à acidez e ao nível de oxidação, o que viabiliza a sua aplicação como matériaprima na produção de biodiesel.

\section{Referências}

1. Openshaw, K. A review of Jatropha curcas: an oil plant of unfulfilled promise. Biomassand Bioenergy, v.19, p.1-15, 2000.

2. Pereira, C.S. S.; Coelho, G. L. V.; Mendes, M. F. Avaliação de diferentes tecnologias na extração do óleo do pinhão manso. (Jatropha curcas L). Revista de Ciência da Vida, v.31, p., 2011.

3. Brum, A.A.S.; Arruda, L. F.; Regitano-d'Arce, M. A. B. Métodos de extração e qualidade da fração lipídica de matérias-primas de origem vegetal e animal. Química Nova, v.32, p.849-854, 2009.

4. Bligh,E.G. and Dyer,W.J. A rapid method for total lipid extraction and purification. Can.J.Biochem.Physiol. 37:911-917, 1959.

5. Melhorança Filho, A. L.; Pereira, M. R. R.; Silva, J. I. C. Potencialidade energética em extratores e tempos de extração do óleo de pinhão-manso (Jatropha curcas L.) em soxletter. Bioscience Journal, v.26, p.226-230, 2010.

6. AOAC (Association Official Analytical Chemistry). Official methods of analysis. 16th ed. Arlington, Vol.2, p.99, 1997.

7. Shantha, N.C.; Decker, E.A. Rapid, sensitive, iron-based spectrophotometric methods for determination of peroxide values of food lipids. Journal of AOAC International, v.77, p.421-424, 1994.

8. AOCS. American Oil Chemists' Society. Official methods and recommended practices of the American Chemists' Society. 3rd ed. Champaign: A.O.C.S., 1989.

9. Fundação Centro Tecnológico de Minas Gerais. Programa Energia: produção de combustíveis líquidos a partir de óleos vegetais. Belo Horizonte: CETECMG, 1983. 152p.

10. Heller, J. Physical nut (Jatropha curcas L.): promoting the conservation and use of underutilized and neglected crops. Rome: International Plant Genetic Resources Institute, 1996. 66p.

11. Gusso, A.P.; Mattanna, P.; Pellegrini, L. G.; Cassanego, D. B.; Richards, N. S. P. S.; Ribeiro, A. S. Comparação de diferentes métodos analíticos para quantificação de lipídios em creme de ricota. Revista do Instituto de Latícinios Cândido Tostes, v.67, p. 51-55, 2012.

12. Ferrari, R. A.; Casarini, M. B.; Marques, D. A.; Siqueira, W. J. Avaliação da composição química e de constituinte tóxico em acessos de pinhão-manso de diferentes origens. Brazilian Journal Food Technology, v.12, p.309-314, 2009.

13. Rodrigues, N.S.; Pereira, L.C.; Carvalho, M.S.R.; Pereira, L.C.; Vieira, J.S.C. Controle de qualidade e obtenção do óleo do pinhão manso (Jatropha curcas L.) por meio da extração mecânica. In: Simpódio Nacional de Biocombustíveis, 5, 2012, Canoas. Resumos. Canoas: 2012.

14. Silva, N. K.; Mansano, M.; Nogueira, R. I.; Freitas, S. P. Obtenção e caracterização de óleo de semente de romã (Punica granatum) por prensagem a frio. In: Congresso Brasileiro de Engenharia Química, 2012, Búzios, RJ. Anais. São Paulo: Associação Brasileira de Engenharia Química, 2012. p. 9989-9995.

15. Carapinha, P.G. Utilização do azeite na fritura de alimentos. 2012. 54f. Dissertação (Mestrado em Engenharia Alimentar) - Instituto Superior de Agronomia, Universidade Técnica de Lisboa.

\section{Juliana A. C. Bento, Maiara O. M. Silva, Nathália P. Silva, Maria A. B. Gonçalves*, Adão W. P. Evangelista, Celso J. de Moura \& Reinaldo G. Nogueira}

Universidade Federal de Goiás, CEP 74690-900, Goiânia, GO, Brasil.

*assima.bittar@gmail.com 